TRABajos de Prehistoria

46, 1989, pp. $279-291$

\title{
PLACAS AUREAS DE LA EDAD DEL HIERRO EN LA MESETA OCCIDENTAL
}

\author{
POR
}

\author{
LUIS BERROCAL RANGEL (*)
}

\begin{abstract}
RESUMEN Este estudio trata de un modelo de joyas áureas peninsulares decoradas con motivos englobados dentro de las temáticas del Arte de la Edad del Hierro Continental pero realizadas con técnicas plenamente orientales que permiten considerarlas como producciones postreras de la orfebreria orientalizante del Occidente Peninsular.
\end{abstract}

\begin{abstract}
This article analyzes two groups of gold plaques from Extremadura. These were made using "orientalizing" techniques (repoussé, stamping, granulation, filigree, and enamels), but the ornamental results (motives and themes) conform to Western European Iron Age tastes.
\end{abstract}

Palabras clave Edad del Hierro. Meseta occidental. Placas áureas. Técnicas orientales. Iconografía occidental.

Entre los hallazgos áureos de los últimos años en las tierras occidentales de la Península, destacan unas pequeñas placas procedentes del castro de La Martela (Badajoz) (Fig. 1) que presentan una identidad formal y técnica con las de otro tesoro hallado cerca de la localidad de Serradilla (Cáceres) (Figs. 2 y 3), ejemplares de un modelo de joyas no documentado, hasta el momento en la Península Ibérica. El estudio unificado de ambos conjuntos permite ahondar considerablemente en el aspecto y función singular de estas placas.

Las piezas de La Martela, tres pequeñas placas trapezoidales y un colgante en forma de bellota, fueron halladas en 1984, al parecer casualmente, por D. Florentino Girol, en la serranía homónima (Segura de León, Badajoz). El lugar, destacado cerro de 812 m. s.n.m., se reveló, tras las oportunas excavaciones, como una estancia periférica de un pequeño poblado, fechada por sus excavadores en los siglos anteriores a la presencia de Roma (Enríquez y Rodríguez, 1985: 10-16 y 1988: 113-128). En el yacimiento, que habíamos prospectado desde 1979, pudimos constatar socavaciones clandestinas, en los días siguientes a la noticia del hallazgo, dada en el periódico regional "Hoy". Junto a una larga franja, de una treintena de centímetros de profundidad, recogimos grandes fragmentos de dos o tres urnas grises globulares estampilladas y puntilladas, parte de un gran vaso, hecho a mano y toscamente alisado y varios cuchillos de hierro. Posteriormente, este lugar sería indicado por D. Florentino Girol, a los arqueólogos encargados de las excavaciones, como el del hallazgo del tesoro y en él se abrió el corte n. 1. En 1987, el Sr. Girol nos permitió dibujar y fotografiar una serie de bronces, hallados por él junto a las placas. Consistían en fragmentos de, al menos, tres fíbulas de apéndice caudal (La Téne I), un disco de atalaje de caballo del tipo de los de Cancho Roano y un alfiler.

(`) Dpto. de Prehistoria y Arqueologia. Universidad Autónoma. Cantoblanco. Madrid. 
El hallazgo de Serradilla fue también producto de una actividad marginal a la Arqueología, las labores de un campo, sin que esta vez fuera posible relacionarlo con un contexto arqueológico (Sayans, 1966 y Almagro Gorbea, 1977: 221 y ss.). Lo componen más de una veintena de piezas, en deficiente estado de conservación, que incluyen seis arracadas, un par de cadenetas y seis placas, junto a fragmentos de otras, de tipo similar a las de La Martela (Fig. 2 y 3 - Lám. 2).

\section{CARACTERISTICAS TECNICAS}

Son grupos de placas trapezoidales de oro, cada una con el lado mayor en la base y el menor soldado a un canalillo de suspensión. Las medidas oscilan entre 3 y $5 \mathrm{cms}$. de anchura, menos de 4 de altura y $1 \mathrm{~mm}$. de espesor (placas: $a=4,7 \times 3,4, c=4,5 \times 3,2$ y $d=5,5, \times 4 \mathrm{~cm}$. de La Martela; $1=2,8 \times 2,8,4=3,2 \times 2,8$ y $5=3,6 \times 3 \mathrm{~cm}$. de Serradilla).

Técnicamente cada placa se compone de dos láminas, la del reverso, lisa y ligeramente mayor y la del anverso, profusamente decorada. La unión de ambas se logra mediante el acabado abarquillado de los bordes de la posterior, que permite el acople de la otra, camuflado por un ribete de cordoncillos trenzados dobles y una hilera de gránulos. Además, en algunos ejemplares se observa la existencia de "grapas" o solapas, prolongaciones de la chapa de reverso, con uno o dos milímetros de anchura, que pasando sobre el cordoncillo se sujetan bajo los gránulos.

Se han empleado las siguientes técnicas ornamentales:

a) Repujado, en la ejecución de motivos realizados en la misma lámina base o bien por separado y posteriormente soldados a ella: la placa n. 3 del conjunto de Serradilla, actualmente rota, permite ver que el motivo central fue repujado y acoplado a la placa por una pestaña de $1 \mathrm{~mm}$. de anchura. Igualmente, parte de un motivo de ave de la n. 6, actualmente desprendido, encaja perfectamente en el hueco dejado sobre la lámina de su anverso. Por lo general se aplica esta última solución a los motivos "principales". La regularidad de ciertas figuras aboga por la utilización de matrices para el estampado.

b) Granulado, se emplea para la sujeción exterior y el silueteado de los motivos repujados y sus rasgos internos (ojos, nariz, alas, etc.), asi como para formar motivos ornamentales de trasfondo y complementarios.

c) Filigrana, con cordoncillos sencillos o trenzados dobles, de sección circular. Se utiliza en los bordes de las placas y para contornear determinadas figuras (rosetas de los ejemplares de La Martela o prótomos contrapuestos de la placa n. 2 de Serradilla). En contados casos se usa en adornos complementarios: en la citada placa n. 2, con bandas de entrelazados en torno a gránulos, hechas con hilo sencillo de sección circular, soldado a la lámina en los cruces; en el motivo circular inferior de la misma placa o en los glóbulos de las piezas de La Martela.

d) Apliques de esmaltes (placas de La Martela) en huecos o alveolos foliformes y pareados, delimitados por una pequeña pestaña soldada sobre la placa y la consiguiente fila de gránulos. Los sistemas de suspensión son estructuras cilíndricas soldadas a los lados menores de las placas, bien formadas por bandas longitudinales independientes, decoradas con estrías cinceladas y agrupadas con arandelas, logrando un continuado abombamiento (como se documenta en La Martela y en tres placas de Serradilla, con la sujeción anular, triple o doble, sólo en los extremos) o bien decoradas con una ancha cenefa de cordoncillos, que forman motivo en espiga y continúa en el borde superior de la placa, entre terminaciones anulares dobles (sólo documentado en Serradilla). Una banda tubular, formada por una filigrana de arillos y flanqueada por cordoncillos dobles trenzados, se observa sobre la pieza $n$. 2 de Serradilla. Su función como elemento sustentante parece clara (Sayans, 1966: 21). Sin embargo, el hecho de estar la placa recortada hasta el punto de haber perdido su forma original, impide ratificar que el citado canutillo sea el medio principal de suspensión o bien complemente a uno de los sistemas descritos o diferente (pieza n. 7, adornada con meandros de filigrana). 


\section{TEMATICA Y COMPOSICIONES DECORATIVAS}

En este apartado hemos considerado oportuno distinguir los motivos principales en la interpretación de las composiciones, de aquellos complementarios de un significado en especial y de los accesorios, que contribuyen al recargamiento decorativo de las placas.

Entre los primeros se repiten las cabezas humanas y de animales mamiferos, las representaciones de aves acuáticas afrontadas, un doble prótomo de anátidas o équidos y motivos cónicos «bellotiformes". Todo ello complementa y refuerza sus valores simbólicos y decorativos con la presencia de numerosos discos concéntricos, glóbulos y rosetas, así como, acompañando a las cabezas de La Martela, con motivos foliformes apuntados hacia abajo. Los elementos accesorios forman bandas o cenefas de filigrana, con cordones diseñando espigas y, en granulado, líneas de triángulos, a veces dobles y contrapuestos. Además, en Serradilla, se documentan pequeños triángulos, rombos y rosetas formados por tres o más gránulos que se colocan en el campo o sobre las figuras principales.

En todas las composiciones abundan glóbulos y círculos que, aún camuflados como ornamentación complementaria, parecen reforzar la simbología del conjunto. Su interpretación como símbolos solares es aceptada por los especialistas en general (Almagro Gorbea, 1977: 229), especialmente cuando se ponen en relación con los motivos a los que aquí acompañan.

Esta supuesta simbologia común, se evidencia aún más con la disposición figurativa, establecida por la asociación de motivos principales, creando grupos de placas homólogas:

\section{Conjunto de La Martela}

a) Roseta y discos «solares" delimitan un par de cabezas humanas frontales, flanqueadas por dos grandes hojas apuntadas hacia abajo (Fig. 1. a). El mismo esquema, con la introducción de un rostro, también frontal, posiblemente de felino, caracteriza la placa $c$ y sirve de nexo con el siguiente modelo.

b) Roseta y discos «solares" delimitan tres prótomos frontales de mamíferos, separados por un par de hojas apuntadas hacia abajo (Fig. 1.d). El suave y gradual estrechamiento de las caras, sus remates superiores ralos y la representación de las posibles orejas, apuntadas hacia delante sobre los grandes ojos, permiten considerarlas, ambiguamente, como representaciones de équidos o cánidos.

\section{Conjunto de Serradilla}

c) Disco «solan» bajo una figura compuesta de un doble prótomo de ave o équido, con cabezas contrapuestas, cuello, tórax y patas (Fig. 2.2). Este motivo está delimitado con un doble cordoncillo trenzado que certifica que la figura está completa, no reconociéndose arranque de alas u otro elemento que ayude en un interpretación. Sobre ella y entre ambos prótomos, una cabeza humana de perfil mira a la derecha, con el cabello indicado, como en La Martela, por hileras de granos y con una posible gargantilla o arranque de vestido, al cuello.

d) Cabeza humana frontal, circundada de glóbulos «solares» (Figs. 2.1 y 3, incluyendo un fragmento de esquina que podría pertenecer a esta placa). La dudosa identificación (Almagro Gorbea, 1977: 229) se debe al mal estado de conservación que impide una observación segura. Sin embargo, su comparación con las piezas de La Martela nos permite interpretarlo como una cabeza humana, vista de frente.

e) Pareja de aves, rodeadas de glóbulos perlados (Figs. 2. 4, 6 y 11). Hay que ratificar el aspecto 


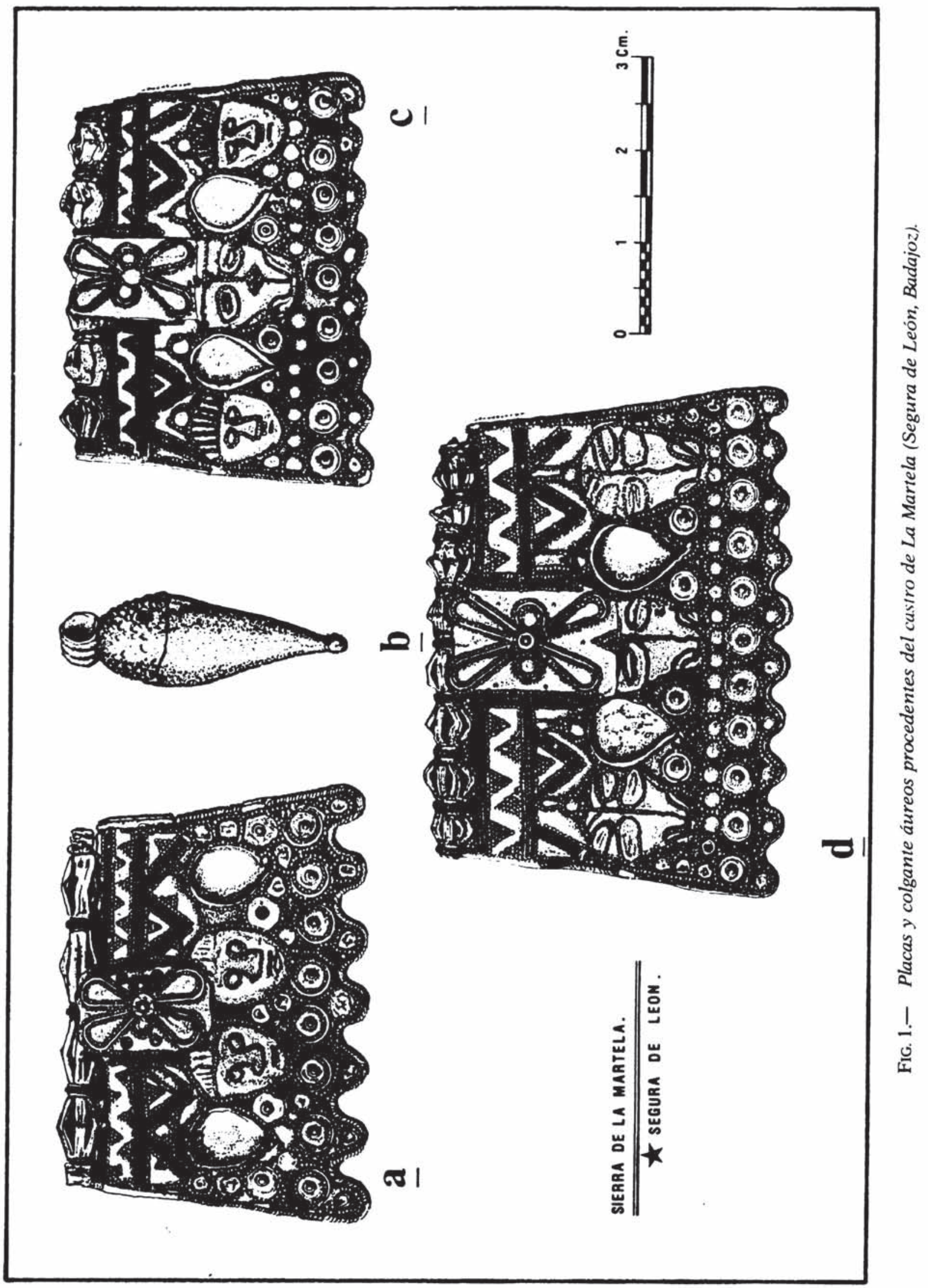




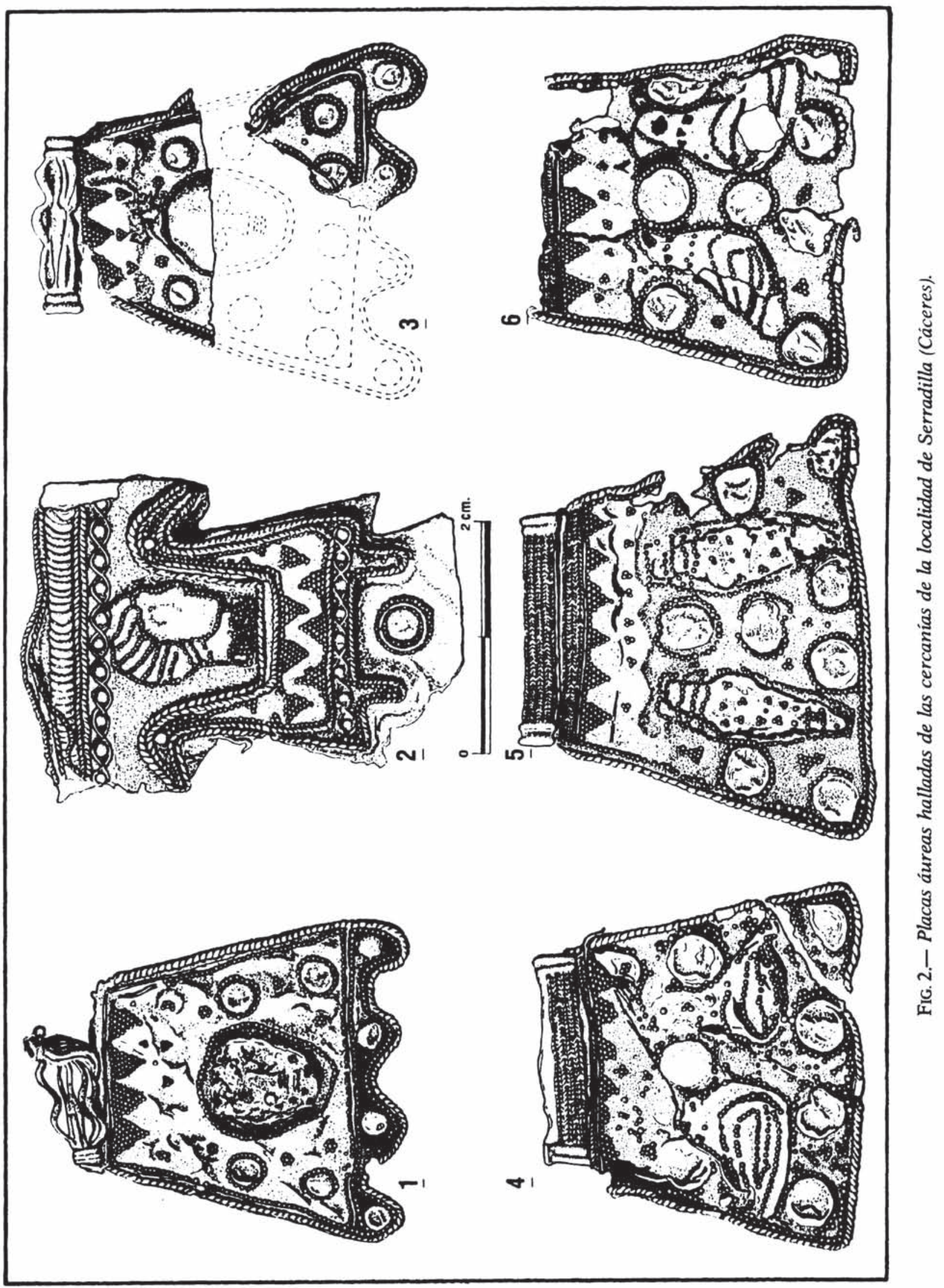




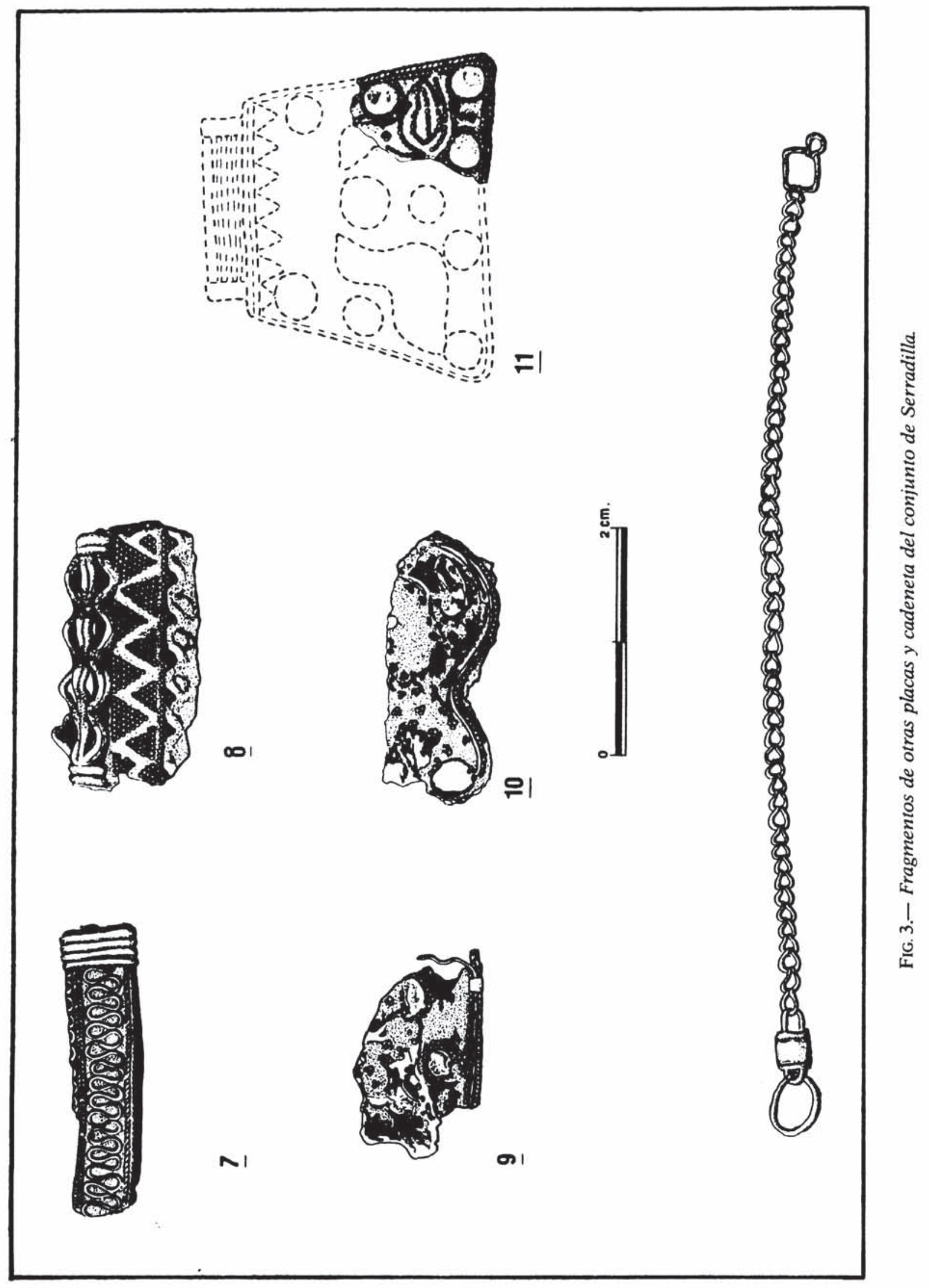


de anátidas postulado por Sayans (1966: 20), especialmente en los ejemplos n. 4 y 11, que responden a una misma matriz.

f) Pareja de figuras alargadas, circundadas por glóbulos perlados (Fig. 2.5). Este motivo central, más controvertido en su identificación, lleva a soluciones diferentes: representación antropomórfica de dos sarcófagos, pese a su falta de realismo (Sayans 1986: 16-17); variantes del "ídolo-botella" conocido en la orfebrería púnica (Almagro Gorbea 1977: 229), aunque difieren notablemente de las recogidas por Quillard (1979: 59-64). El estudio en conjunto nos lleva a bascular con la consideración de alargados colgantes cónicos, quizás bellotas, semejantes al ejemplar de La Martela, aunque con todas las reservas expresadas.

\section{VALORACION CULTURAL}

Estas piezas muestran una ejecución y técnica típicamente oriental y mediterránea. Paralelos técnicos específicos en la orfebrería de este ámbito geográfico fueron recogidos por Almagro Gorbea (1977), aunque las joyas, en cuanto a su concepción general son raras en este amplio mundo.

En la orfebrería orientalizante de la isla de Rodas (s. VII a. C.) encontramos series o conjuntos de placas colgantes con figuras y rosetas (Fig. 4) (Laffineur, 1978: 166-184 y 1980: 13-29), que llaman la atención, no ya por la personalidad de los modelos sino por la completa concordancia técnica y de ejecución con las extremeñas, rasgo que, por su complejidad y peculiaridad, permite considerarlas como antecedentes, al menos técnicos, de las hispánicas. También muestran una lejana relación en el transfondo oriental representado: figuras de la "potnia theron" dedálica, con leones o pájaros y cabezas «hathóricas» frontales, felinos y rosetas, etc. (Laffineur, 1979: 11-66).

Sin embargo, y sin negar este antecedente, la iconografía de las piezas extremeñas presenta soluciones formales que parecen responder a gustos y creencias propios de culturas occidentales.

Las cabezas representadas en las placas de La Martela y posiblemente las de Serradilla responden a cánones (la forma general de la cara, la unión de ojos y nariz en una sola línea, la falta de orejas o la ejecución sencilla del pelo, que podría reproducir su remate en moño, con el círculo que corona las cabezas -Fig. 1. c-), propios de modelos celtas con influencias mediterráneas (Fig. 5. a) (Jacobsthal, 1969: 12-16 y 21), identificación que se refuerza con las representaciones de hojas apuntadas hacia abajo que las flanquean, rasgo específico de las cabezas célticas que para Jacobsthal (1969: 22-24) y Megaw (1970: 27) denotan cierto grado de sacralidad o relevancia unido a una función profiláctica.

La presencia de rostros y cabezas humanas, en posición frontal, en importantes joyas "orientales" del SO. como las de la Aliseda y Evora, no sirven más que para reafirmar la gran diferencia morfológica y de ejecución que tienen con los modelos aquí tratados. En el primer caso, un anillo y. en el segundo, la famosa diadema y unos colgantes muestran parejas de rostros afrontados cuyos contornos y rasgos estrechos y alargados recuerdan al concepto oriental de la doble cara contrapuesta, según apuntó Blanco de Torrecillas (1959: 52-54) y Almagro Gorbea (1977: 209 y XXXII). Todo lo contrario ocurre con los paralelos, en general posteriores, conocidos en la Hispania tradicionalmente denominada "céltica", como veremos después (López Monteagudo, 1987: 245-252). Sin embargo, dentro de la constante simbiosis entre lo oriental y lo occidental que caracteriza la orfebrería y teoréutica del Occidente europeo, es importante apuntar la existencia de estos precedentes en la iconografía orientalizante del SO. peninsular.

La conjunción de la figura humana y el caballo, quizás reflejo del culto al "despótes o a la pothnia híppon", tan difundido en la Protohistoria Europea (Egg, 1986: 69-78; Blázquez 1958: 162175 y 1983: 189; Maluquer de Motes, 1981: 330), podría reflejarse en los conocidos bocados de Cancho Roano (Fig. 5. b) y se conjuga con el aspecto funerario y de tránsito que Maluquer de Motes 


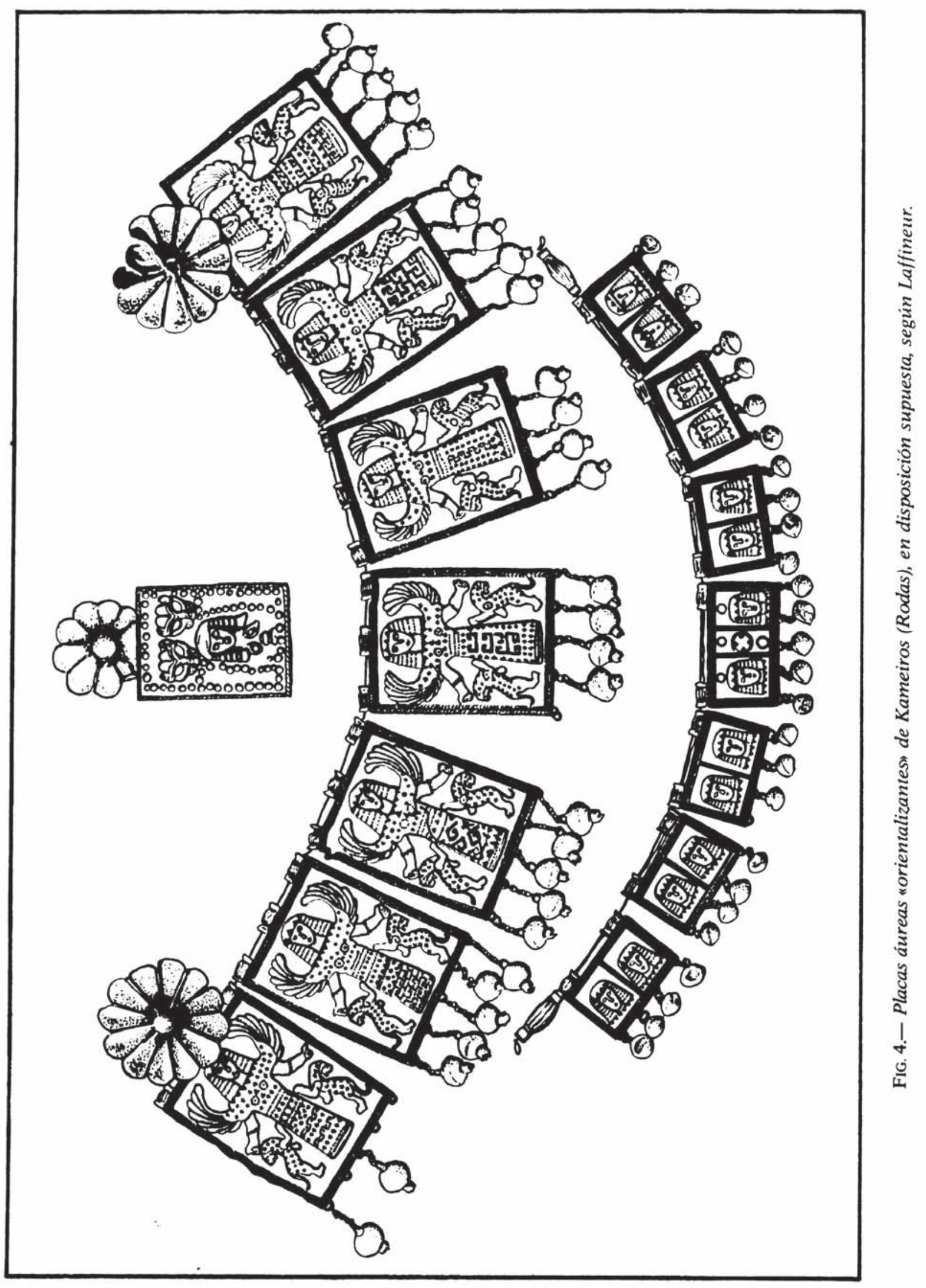


(1981: 324-333) propone para el contexto arqueológico de estos hallazgos de Zalamea y para la forma barquiforme similar del "bronce" de Carriazo (Fig. 5. c), interpretado como «barco solar" dentro de una rica simbologia alpina (idem 1957: 160-162). Este mismo significado fue usado por Sayans (1966: 42) y Almagro Gorbea (1977: 229) para explicar el esquema de la placa n. 2 de Serradilla (Fig. 2.2), en la que, como en el «bronce» de Carriazo, la figura humana sustituye al disco solar entre anátidas de la composición centroeuropea.

El problema de esta identificación estriba en la falta de atributos orientales y femeninos en la placa de Serradilla, que carece incluso del tradicional peinado "hathóricon de la pieza de Carriazo. Por el contrario, la cabeza es de aspecto varonil, semejante al "despótes híppon" de Cancho Roano (Fig. 5. b); el prótomo doble posee una parte inferior llana con representación de patas, que lo aleja de la convencional forma de barco, vista en los ejemplos apuntados, y sus cabezas no permiten con certeza catalogarlas como cisnes (Sayans, 1966: 20 y Almagro Gorbea, 1977: 223 y 229) y bien podrían ser caballos, tal como parecen sugerir las patas y la "panza" plana.

De todas formas parece poco discutible la relación solar y de tránsito, reforzada por la presencia de aves y discos en las otras placas del conjunto cacereño, trasfondo que en regiones de Europa septentrional es aplicado también al carro (Kossack, 1954: I y IV, 7-9) y en ámbitos similares, a toda la serie de "placas colgantes» trapezoidales y triangulares que se localizan por la Región Alpina, decoradas con un rostro humano frontal sobre prótomos de caballos, rodeados de glóbulos y discos perlados, así como pájaros, colgantes cónicos y bellotas (Egg, 1986: figs. 1-4; XIV. 1). Aunque estas placas-colgantes no sean las mismas que las peninsulares, no nos caben dudas sobre la gran relación existente entre ambos modelos. Más aún observamos las mismas temáticas iconográficas en algunas representaciones de la Meseta Norte, en épocas más tardías, como las pintadas sobre cerámicas de Numancia y Uxama o las del utesoro" de plata de Drieves (Guadalajara) (San Valero, 1945: fig: 3 y López Monteagudo, 1987: 250).

Las demás placas extremeñas reflejan significados análogos: las cabezas, figuraciones del posible culto galo a la "tête coupée" (Chassaing, 1976: 69 y ss.), común a las poblaciones del Oeste peninsular, como pudiera testimoniar el interesante cráneo del vecino depósito de Garvâo (López Monteagudo, 1987 y Beirâo et alii, 1985: 60) y la conjunción de ánades con discos "solares", son los adornos de grandes calderos de la necrópolis de Hallstatt (Megaw, 1970: 51, XXI-XXII), de sítulas, ánforas, armaduras y demás teoréutica alpina (Von Mehart, 1969: XLIV-L; Jacobsthal, 1969: 297, 365 y 393. $a-d$ ) y con la misma disposición que en Serradilla, de un grupo de seis torques del Marne y de una fíbula suiza (Fig. 5 d,e) (Kossack, 1954: Jacobsthal, 1969: 14 y 27-30; Megaw, 1970: 51), que responden a fenómenos de aculturación en regiones de contacto entre pueblos continentales y mediterráneos (Nash, 1985: 45 y ss., 55-63).

Esta integración permite considerar el motivo central de la pieza n. 2 de Serradilla como símbolo de creencias de "tránsito y resurreción" muy unido al tema del "hombre desnudo entre aves y monstruos" de los broches calados de cinturón del Valle del Marne y de Ticino (s. V. a. C) o al de "la señora de los caballos" de las placas alpinas, versiones de «la señora o señor de las aves, caballos o felinos" oriental con los que tienen un nexo en pendientes calados de tumbas de Chiusi y Vetulonia (ss: VIII y VII a. C.) y otras producciones de Italia Central (Megaw, 1970: 84-85 y Egg. 1986: 76).

En un contexto simbólico semejante deben encuadrarse los dos motivos centrales de la placa n. 5 de Serradilla y el colgante "bellotiforme» de la Martela (Fig. 1. b), reflejos de una temática muy repetida en la orfebrería alpina, danubiana y griega del siglo V y su hinterland (Egg. 1986; Marshall, 1911: nos. 1944-58; San Nicolás, 1986: 78-80), donde como las granadas y otras representaciones vegetales, se muestran como símbolos del ciclo vital, del tránsito y del renacer (Laffineur, 1978: 178).

\section{FUNCIONALIDAD}

El uso y destino de estas joyas nos es desconocido por la falta de un contexto arqueológico 


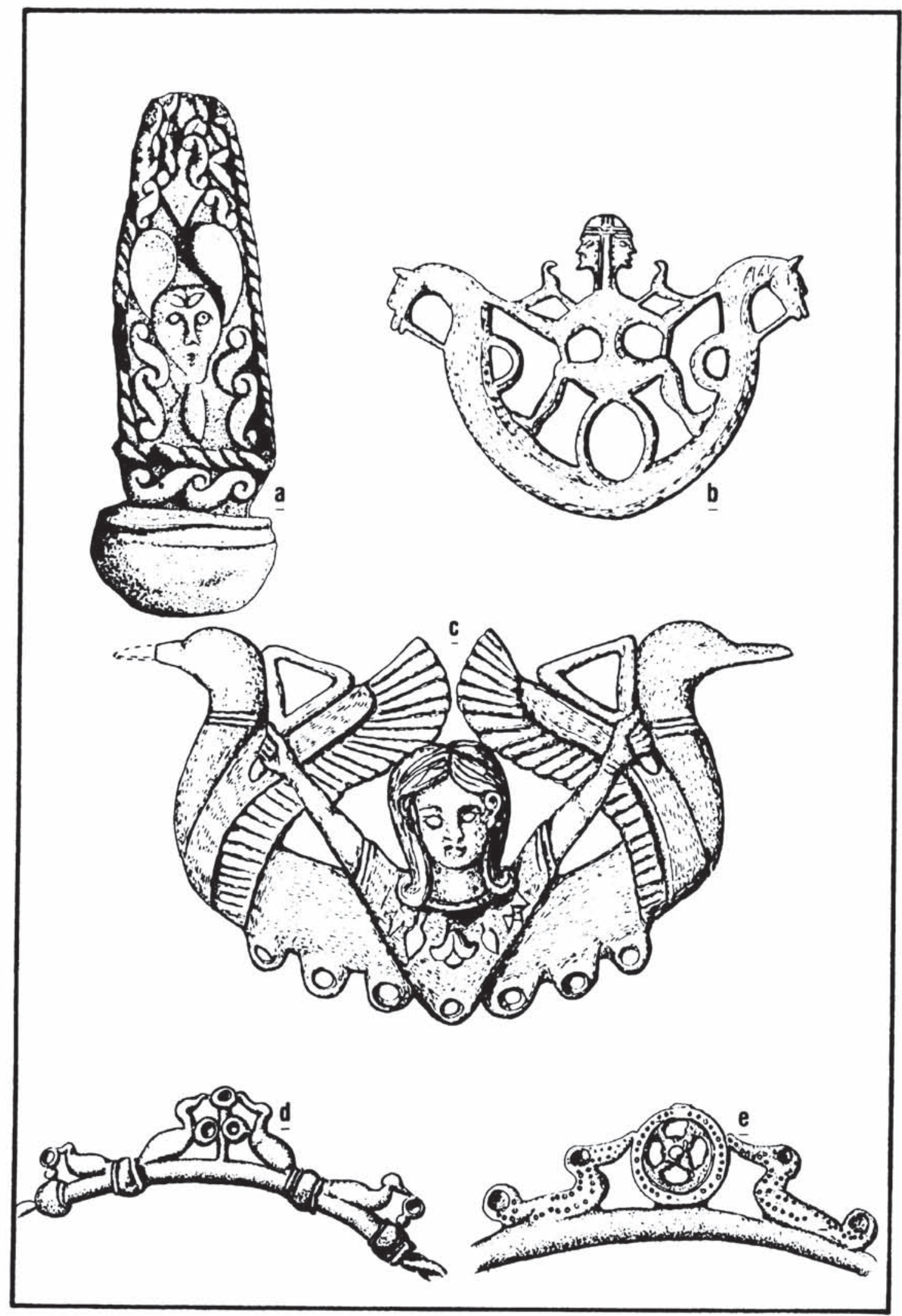

Fig. 5.- a.- Pilar de Pfalzfeld (Alemania); b.- Bocado de atalaje de caballo procedente de Cancho Roano (Badajoz): c.- "Broncen de Carriazo; d. y e.- Torques procedentes de túmulos del valle del Marne. Todos ellos según fotografias. 
especifico. Por sus semejanzas rodias sería plausible considerarlas elementos de collares pectorales, supuesta función de estas joyas orientales.

Como las placas extremeñas, forman conjuntos en serie y quedan suspendidas por el lado superior mediante un cordoncillo que pasa a través de un sistema tubular. La colocación de estas piezas para Laffineur (1978: 79 y 1980: 26), Higgins y otros debia ser sobre el pecho, estando prendidos los extremos al vestido en los hombros, por medio de fíbulas o alfileres, disimuladas con una roseta. Paralelos en el Arte Griego, como algunas figuras del vaso "François" confirman este uso (Fig. 6. a) (Jacobsthal, 1956: 110, figs: 331-332).

Ciertamente las placas rodias son rectangulares y no plantean los inconvenientes funcionales de nuestros ejemplares, trapezoidales, que se taparían parcialmente entre sí. Esta razón aporta Laffineur, para no considerarlas como piezas suspendidas del cuello, y es definitiva para descartar el uso de las placas extremeñas en diademas o coronas de placas rectangulares portadas por las imágenes de "Astarté» y sugerido para las placas del Carambolo (Blázquez 1983, 40). Solución a este problema se encuentra intercalando en el hilo sustentante cuentas longitudinales semejantes a los canutillos de suspensión de las placas de La Martela o sencillamente colocando las placas en collares de cuentas, como un ejemplar de la tumba Benvenuti (Este) (Fig. 6. c) (Randall-McIver, 1927).

Con todo, la consideración de colgantes únicos en collares, como los trapezoidales de ciertas terracotas etrusco-campanas (Bedello, 1974: 96-98) no se descarta ni siquiera para las piezas rodias (Laffineur, 1978: 80). Un collar pectoral, del segundo tesoro de Boukyovtsi (Bulgaria), siglo IV a. C. muestra conjuntos de colgantes con cabezas, rosetas, granadas y bellotas, que penden de varias fíbulas unidas por cadenitas (Fig. 6. b) (Venedikov, 1976: 61). Su iconografía recuerda tanto la de las placas extremeñas como las de Rodas, hasta el punto que para Laffineur (1978: 168), collarespectorales como éste, muy extendidos por el norte de Grecia y el cauce del Danubio, son derivados de la orfebrería rodia del siglo VII a. C. En este sentido hay que recordar las fíbulas de La Tène, halladas junto al tesoro de La Martela e incluso las arracadas y cadenitas que acompañan a las placas de Serradilla.

Respecto a la función de estas piezas, se puede barajar un valor profiláctico junto a la consideración de bienes de prestigio entre los pueblos de la Meseta, comparable a las piezas denominadas "céltico-orientalizantes" de Francia, Suiza e Italia (Sandars, 1976: 41-55; Megaw, 1975: 15-33 y Jacobsthal, 1969: 22), reflejos de las relaciones entre los pueblos costeros mediterráneos y los jefes guerreros celtoparlantes del interior para los que se fabricaban, siguiendo viejas técnicas y tipologías orientales, joyas de iconografía y simbología al gusto occidental (Nash, 1985: 55-63).

\section{CRONOLOGIA}

Las características técnicas de las piezas de Serradilla, a caballo entre tesoros orientalizantes y la orfebrería castreña del Noroeste, indujeron a datarlas en el siglo V a. C. (Almagro Gorbea, 1977: 229-230).

Las placas de La Martela se fecharon en el siglo IV a. C. en razón del contexto arqueológico supuesto y sus analogías técnicas con los tesoros de Evora y Arrabalde (Enríquez y Rodríguez, 1985: 11). Aunque la gran calidad de las piezas las aproximan y equiparan a ejemplares "orientales" peninsulares como los de Evora y Aliseda, los paralelos iconográficos antes apuntados y la presencia de abundantes productos griegos del siglo $\mathrm{V}$ a. $\mathrm{C}$ en enclaves (el Castañuelo y el castro de Azougada) de la misma comarca del Ardila (Del Amo, 1978: Rouillard. 1974), abogan por la ampliación hacia Occidente de rutas comerciales griegas y etruscas, y por una fecha y contexto semejante para las placas aquí estudiadas. 


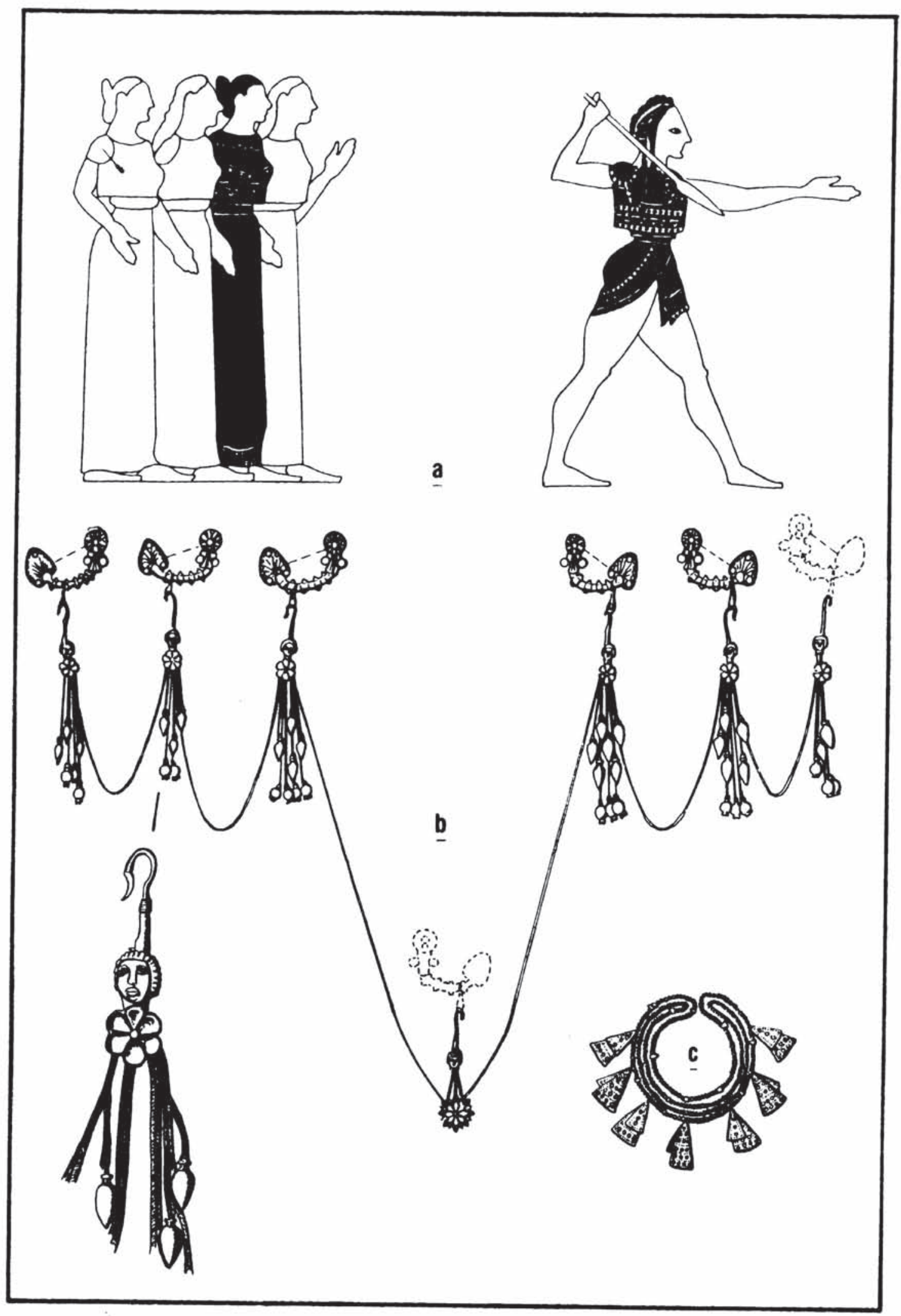

FIG. 6. - a.- Figuras portando collares pectorales, prendidos de los hombros con alfileres. Vaso "François;; $b$.Collar pectoral de Boukyovtsi (Bulgaria); c.- Collar de placas de la tumba de Benvenuti (Este). 


\section{BIBLIOGRAFIA}

Almagro Gorbea, M. (1977): El Bronce Final y el Periodo Orientalizante en Extremadura. BPH, XIV, Madrid.

Bedello, M. (1974): Terracotte votive, III. Capua Prerromana, Sansonic Editore. Capua.

BeIrAo, C. de, et alii. (1985): "Depósito votivo da II Idade do Ferro do Garvâo. O Arqueólogo Português. III, 4: 45135.

Blanco de Torrecilla, C. (1959): "El tesoro del cortijo de Evora». Archivo Español de Arqueologia, XXXII: $50-57$.

BLÁzouez, J. M. (1958): “El "despotes therón” en Etruria y en el Mundo Mediterráneo». Zéphyrus, IX: 162-175.

- (1983): Religiones Prerromanas. (Primitivas Religiones Ibericas), Madrid.

Chassaing, M. (1976): "Du rite celtique des têtes coupées et de sa survivance dans l'iconographie gallo et germano-romaine (I). XX Congrés Préhistorique France (1974): 69 y ss.

Del Amo, M. (1978): "El Castañuelo. Un poblado céltico en la provincia de Huelva». Huelv'a Arqueológica, IV: 299. 340.

EGG, M. (1986): «Die "Herrin der Pferde” im Alpengebiet». Archäologische Korrespondenzblatt, 16: 69-78.

Enriquez Navascués J. J. y Rodriguez Diaz, A. (1985): Las piezas de oro de Segura de León y su entorno arqueológico. Editora Regional de Extremadura. Badajoz.

- (1988): «Campaña de urgencia en la Sierra de La Martela (Segura de León, Badajoz)». Extremadura Arqueológica, I: 113-128.

JacoBStHAL, P. (1956): Greek Pins and their connexions with Europe and Asia. Oxford.

- (1969.2a): Early Celtic Art. I, Oxford.

KossaCK, G. (1954): Studien zum Symbolgut der Urnenfelder und Hallstattzeit Mitteleuropas. Romisch-Germanische Forschungen. Berlin.

Laffineur, R. (1978): L'Orfèvrerie Rhodienne Orientalisante. Travaux et Mémoires de l'Ecole Française d'Athénes, XXI. París.

- (1980): «L'Orfèvrerie Rhodienne Orientalisante». En T. Hackens (Ed.): Etudes d'Orfèvrerie Antique. Aurifex, 1: 13-29.

López Monteagudo, F. (1987): “Las “cabezas cortadas” en la Peninsula Ibérica». Gerión, 5: 245-252.

MALUQuer DE MoteS, J. (1957): "De metalurgia tartesia: el bronce de Carriazon. Zéphyrus, VIII: $160-162$.

- (1981): "El Santuario protohistórico de Zalamea de la Serena, Badajoz" Andalucia y Extremadura: 225-410. Barcelona.

MaRSHALl, F. N. (1911): Catalogue of the Jewellery Greek, Etruscan and Roman in the Departments of Antiquities. British Museum. London.

Megaw, J. V. S. (1970): Art of the European Iron Age. Bath.

- (1975): "The Orientalising Theme in Early Celtic Art: East or West?». En J. Fitz (Ed.): The Celts in Central Europe. Papers of the II Pannonia Conference (1974): 15-33.

NASH, D. (1985): "Celtic territorial expansion and the Mediterranean World". En S. Champions y J. Megaw (Ed.): Settlement and Society: Aspects of West European Prehistory in the First Millenium B. C. Leicester U. P.: 4563.

QuiLlard, B. (1979): Bijoux Carthaginois, I. Les Colliers. Aurifex, 2. Lovaine-la-Neuve.

RANDALL-MCIVER, D. (1927): The Iron Age in Italy.

Rouillard, P. (1975): "Coupes attiques à figures du IV siècle en Andalousie». Melanges de la Casa de Velázquez, $X I: 21-49$.

SANDARS, M. (1976): «Orient and Orientalising: recent thoughts reviewed». En P. Duval y C. Hawkes (Ed.): Celtic Art in Ancient Eurnpe.: 41-55.

SAN NicolÁs, P. (1988): "Orfebrería púnica: los collares de Ibiza en el Museo Arqueológico Nacional de Madrid". Saguntum, 20: 59-94.

San VAlero Parisi, J. (1945): El tesoro preimperial de plata de Drieves. (Guadalajara). Informes y Memorias, 9. 90 pp. Madrid.

Sayans CASTAÑos, M. (1966): Joyas celtas de Serradilla. Plasencia.

Venedikov, I. (1976): "Trhacian Treausures from Bulgaria». En R. A. Higgins (Ed.): The Trustees of the British Museum. London.

Von Mehart, G. (1969): „Hallstatt und Italien». En G. Kossack (Ed.):: Gesammelte Aufsatze zur Frühen Eisenzeit in Italien und Mitteleuropa (Ed. G. Kossack). Mainz. 